\title{
Implicações psicológicas da pobreza na vida do povo latino- americano
}

\author{
Psychological implications of poverty in latin american people's lives
}

Elívia Camurça Cidade ${ }^{[a]}$, James Ferreira Moura Junior ${ }^{[b]}$, Verônica Morais Ximenes ${ }^{[c]}$

\footnotetext{
${ }^{[a]}$ Psicóloga, Mestranda do Programa de Pós-Graduação em Psicologia da Universidade Federal do Ceará, bolsista CAPES/Demanda Social, Fortaleza, CE - Brasil, e-mail: elivia_nucom@yahoo.com.br

${ }^{[b]}$ Psicólogo, Mestrando do Programa de Pós-Graduação em Psicologia da Universidade Federal do Ceará, bolsista CAPES/REUNI/Propag, Fortaleza, CE - Brasil, e-mail: jamesferreirajr@gmail.com

${ }^{[c]}$ Psicóloga, Doutora em Psicologia (Universidade de Barcelona), professora da Graduação e da PósGraduação em Psicologia da Universidade Federal do Ceará, Fortaleza, CE - Brasil, e-mail: vemorais@yahoo.com.br

Recebido: 02/11/2010 Received: $11 / 02 / 2010$

Aprovado: 23/03/2011 Approved: 03/23/2011
}

\section{Resumo}

O presente artigo tem como objetivo apresentar as reflexões empreendidas sobre a emergência da categoria pobreza e suas possibilidades de diálogo com a Psicologia tomando como cenário a realidade latino-americana e brasileira. Para tanto, parte-se da discussão da pobreza a partir de um enfoque multidimensional, que coloca em evidência a impossibilidade de que esse fenômeno seja capturado somente a partir de questões monetárias. Ao contrário, coloca-se em pauta a necessidade de se pensar a realidade psíquica, simbólica e política vivida por sujeitos nessas condições. A pobreza, uma das manifestações do processo de marginalização ao qual foi submetido o povo latino-americano, contribui para o desenvolvimento de formas singulares de estruturação do psiquismo. Apesar da pobreza e da realidade social da América Latina constituírem de forma singular o psiquismo humano, este sujeito deve ser compreendido como potencial e em expansão, não anulando sua capacidade de enfrentar e de transformar uma realidade social opressora. Neste estudo de natureza bibliográfica, são, portanto, apresentadas categorias psicológicas emergentes em condições de pobreza, tais como a Ideologia de Submissão e de Resignação (Góis, 2008), a Cultura da Pobreza (Martín-Baró, 1998), a Cultura do Silêncio (Freire, 1980) e a Síndrome Fatalista (Martín-Baró, 1998), demonstrando a capacidade do indivíduo de (re)agir diante de condições de vida que lhes são dolorosas. Por conseguinte, a observação dessas categorias contribui para enfatizar a possível e necessária implicação da psicologia com os sujeitos que se encontram em condições de opressão, desnaturalizando concepções e anunciando compreensões a partir do ponto de vista dos sujeitos.

Palavras-chave: Pobreza. Psicologia. América Latina.

\section{Abstract}

This article aims to present reflections undertaken on the emergence of poverty category and its possibilities of dialogue with Psychology, considering the Latin American and Brazilian scenario. For that purpose, it starts with a discussion of poverty from a multidimensional approach, which highlights the impossibility of capturing this phenomenon only from a monetary point of view. Rather, the need to think on the psychological, symbolic and political realities experienced by subjects in these conditions must be considered in the agenda. Poverty, a manifestation of the marginalization process Latin American people has been submitted, contributes to the development of peculiar forms of psyche structuring. Despite the fact that poverty and the social 
reality of Latin America constitute the human psyche in a unique way, this individual must be perceived as a potential and growing one, not deleting his ability to confront and transform an oppressive social reality. Thus, in this bibliographical study psychological categories emerging from poverty conditions are presented, such as the Ideology of Submission and Resignation (Góis, 2008), Culture of Poverty (Martín-Baró, 1998), Culture of Silence (Freire, 1980) and Fatalism Syndrome (Martín-Baró, 1998). These categories demonstrate the ability of individuals to (re) act before life conditions which are painful to them. Consequently, the observation of these categories helps emphasizing the possible and necessary implication of psychology to the subjects who are in conditions of oppression, denaturalizing concepts and announcing discoveries from the subjects' viewpoint.

Keywords: Poverty. Psychology. Latin America

\section{Introdução}

Já na segunda metade do século XX, Josué de Castro (1908-1973) demonstrou sua indignação diante dos poucos trabalhos que traziam a fome como elemento central. Nas palavras deste autor

[...] É realmente estranho, chocante, mesmo a observação, o fato de que, num mundo como o nosso, caracterizado por tão excessiva capacidade de se escrever e de se publicar, haja até hoje tão pouca coisa escrita acerca do fenômeno da fome, em suas diferentes manifestações (Castro, 2004, p. 11).

Hoje, cerca de cinquenta e sete anos após esta declaração, ainda há, no meio científico, indagações quanto ao fenômeno da fome, compreendida como uma das múltiplas expressões da pobreza.

Por conseguinte, a emergência da compreensão da pobreza a partir do enfoque multidimensional (Sen, 2000), anuncia a impossibilidade de que esse fenômeno seja capturado somente a partir de questões monetárias. Ao contrário, coloca-se em evidência a necessidade que seja compreendida a realidade psíquica envolvendo a simbólica, a política e o concreto vivido por sujeitos nessas condições.

Conforme afirma Góis (2003, p. 71), o pobre, em certo sentido, possui uma existência que não o pertence, afinal

Nasce na miséria, vive na perseguição e morre no anonimato ou na indigência. Sua pobreza é geral - lhe tiram a chance de viver e de desfrutar dos bens e alimentos; procuram destruir sua voz e sua capacidade de transformar a si mesmo e a realidade em que vive.
Contudo, embora haja uma negação constante do potencial de vida dos indivíduos pobres, materializada por meio da repressão psicossocial, econômica e política (Góis, 2003), há também, em contrapartida, uma (re)ação constante, originadora de alternativas peculiares de vida. Assim, mesmo na condição de negados, indivíduos e povos podem descobrir um sentido de "ser mais", de ser livre e de ser ético (Góis, 2008).

0 trilhar deste caminho, deve partir, inicialmente, de um processo de denúncia das situações de opressão e do anúncio de novas formas de vida. Lança-se, portanto, um convite à psicologia, que historicamente se omitiu das discussões acerca das condições de marginalização as quais estão submetidos inúmeros povos latino-americanos (Martín-Baró, 2009; Osório, 2009). Afinal, em que essa realidade de pobreza interessa a psicologia? Como a psicologia pode, de fato, contribuir para solucionar essas questões?

Diante desses questionamentos o presente artigo objetiva apresentar as reflexões empreendidas sobre a emergência da categoria pobreza e suas possibilidades de diálogo com a Psicologia. Para tanto, baseia-se em um preliminar levantamento bibliográfico sobre a realidade de opressão, marginalização e pobreza vivida pelos povos latino-americanos.

Dessa forma, inicialmente, será apresentada a pobreza sob a ótica multidimensional (Sen, 2000), uma vez que esta é coerente com a compreensão de bem-estar humano presente neste trabalho. Em seguida, a realidade latino-americana e brasileira será abordada como espaço fomentador de questionamentos e novas elaborações para a psicologia, que vem sendo, cada vez mais, convidada a se posicionar e anunciar possibilidades de transformação social condizentes com a realidade dos povos. 


\section{A emergência da categoria pobreza}

Neste estudo compreende-se a pobreza como uma realidade de privação multidimensional (Sen, 2000) na qual o ser humano pode estar situado em uma posição de cerceamento de realização de suas necessidades de alimentação, moradia, de segurança, de educação, de lazer e de saúde. 0 indivíduo, também, pode encontrar-se envolto em correntes ideológicas de marginalização e de culpabilização pela sua situação. Dessa forma, a pobreza é vista como um estado no qual o ser humano está inserido em condições adversas de sobrevivência material e simbólica.

Entretanto, ao serem empreendidos estudos sobre a pobreza, percebe-se que, em um âmbito vigente, as compreensões sobre tal se parametrizam somente em um enfoque monetário. Volta-se, assim, para uma perspectiva capitalista em que as necessidades humanas são reduzidas a meio de trocas mercantis (Lacerda, 2009; Sprandel, 2004).

A partir desse enfoque, a pobreza é reduzida a uma deficiência nas atividades consumistas ou na renda monetária. 0 indicador de bem-estar da pessoa é o consumo (Laderchi; Saith \& Stewart, 2003). Estipula-se, então, um parâmetro de consumo para descrição da pobreza. Configura-se a criação da concepção de linha de pobreza, segundo a qual as pessoas pobres seriam aquelas que estariam abaixo desse patamar (Néri, 2007).

Despreza-se, assim, a heterogeneidade dos indivíduos, de seus contextos sociais, de suas culturas e de suas liberdades pessoais, aspectos estes que não estão representados na lógica do mercado, mas que afeta o bem-estar do sujeito (Salama \& Destremau, 2002; Sen, 2000). Focalizar a pobreza apenas como uma insuficiência monetária é, para Sen (2000), desprezar outros fatores que são constituintes do bem-estar do ser humano. Essa autora é uma das principais responsáveis pela evidência da compreensão multidimensional da pobreza a partir da criação da Abordagem das Capacidades. ${ }^{1}$

Para esta Abordagem não basta que os indivíduos possuam meios, como bens primários e renda, para não serem considerados pobres. Ao contrário, a pobreza se expressa quando as pessoas não têm a capacidade de transformar esses meios em fins, ou seja, em funcionalidades. Na abordagem monetária, contudo, mensuram-se os meios, desprezando os fins ou as funcionalidades existentes em um contexto (Diniz \& Arraes, 2007).

Na Abordagem das Capacidades, há prerrogativas filosóficas e ideológicas que situam o ser humano como ativo na transformação da realidade, estando em um movimento de expansão de suas liberdades. Essas são as capacidades reais que os indivíduos possuiriam para realizar os fins desejados, ou seja, as liberdades substantivas existentes. Além disso, o ser humano é compreendido como repleto de potencialidades que são contextuais, sociais, culturais e pessoais (Sen, 2000).

Sawaia (2009) aproxima-se dessa compreensão ampliada da pobreza, pois defende que o sujeito é um ser em expansão, expressando que a realidade marginalizante e opressora da pobreza poda a capacidade do ser humano de viver em liberdade, pois cerceia a sua capacidade criativa de imaginar.

Assim, neste estudo, a pobreza é considerada como um estado de privação da liberdade oriundo de estruturas marginalizantes e opressoras. Esse cerceamento se manifesta tanto nos níveis macrossocial e microssocial de uma sociedade, como nas formas de privação de liberdades presentes nas interações sociais. Tais fatores dizimam a realização das funcionalidades dos seres humanos, ou seja, exterminam as intenções do indivíduo de viver do modo que lhe convier mais adequado.

Como cenário de compreensão multidimensional da pobreza, percebe-se que a América Latina se situa como uma realidade em que a pobreza é evidenciada em suas ramificações sociais, políticas, estruturais e ideológicas. Significa dizer que a pobreza está expressa em diversos âmbitos, seja na insuficiência de renda de uma significativa parcela da população latinoamericana; nos governos geralmente centralizadores de riqueza; nas crenças que visualizam a pobreza como indigna, ruim e perigosa; ou na organização societária que anula as possibilidades de mudança das trajetórias dos indivíduos pobres.

\footnotetext{
1 Nesse artigo, os termos Abordagem das Capacidades e Abordagem das Capacitações são sinônimos.
} 


\section{Expressões da Pobreza na realidade latino-americana e brasileira}

Vivem na América Latina cerca de 550 milhões de pessoas (Cepal, 2009), sendo que, segundo Sprandel (2004), a realidade desses indivíduos pauta-se em uma dinâmica opressora desde o período de colonização. Como consequência de tal fenômeno, observa-se a criação de modelos societários baseados na violência, na marginalização dos povos nativos, na restrição de movimentos populares e libertários.

Martín-Baró (1998) afirma que a realidade latino-americana está impregnada de pobreza e de opressão. Nesse território houve uma preponderância, até fim do século XX, de governos ditatoriais que cerceavam a liberdade de expressão, aumentavam os índices de pobreza, não distribuíam as riquezas dos seus países com a maioria da população e tentavam anular qualquer forma de movimentações democráticas.

Percebe-se, igualmente, o Brasil constituído desses traços, acrescentando-se a eles práticas políticas clientelistas e assistencialistas mantenedoras da ordem social (Mendonça, 2006; Sprandel, 2004). Evidencia-se, assim, um contingente populacional de 183.987.291 brasileiros (IBGE, 2007) que compartilham essa realidade histórica de opressão na América Latina (Figura 1).

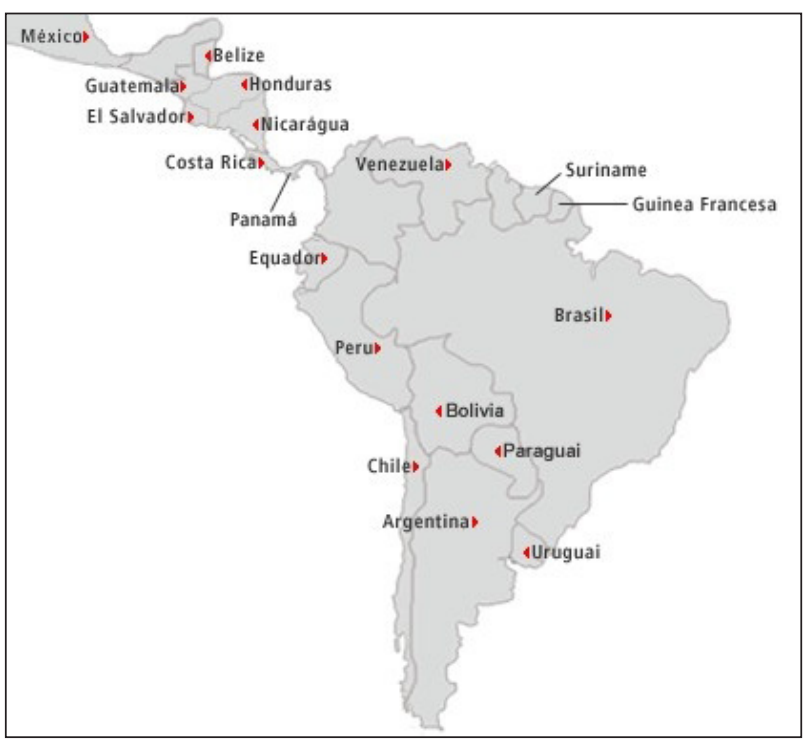

Figura 1 - Mapa dos países componentes da América Latina, onde está situado o Brasil

Fonte: Avis (2010).
Segundo dados da Comissão Econômica para a América Latina e o Caribe (Cepal, 2009), vinculada à Organização das Nações Unidas (ONU), em 2008, a incidência da pobreza vinculada a parâmetros monetários da população da região latino-americana alcançou 33\%, incluindo 12,9\% que viviam em condições de pobreza extrema ou indigência. Estes valores correspondem a um montante de 180 milhões de pessoas pobres e 71 milhões de indigentes, que sobrevivem com o mínimo necessário para satisfazer suas necessidades alimentares.

Em relação ao Brasil, observa-se que, no ano referido, dos 189.820.330 habitantes brasileiros, aproximadamente 57,5 milhões viviam em condições de pobreza (vivendo com $1 \frac{1}{2}$ salário mínimo²), 23,8 milhões em condições de indigência ou miséria (renda per capita de 1/4 de salário mínimo) e 10,3 milhões na extrema indigência ou extrema miséria, sobrevivendo com $1 / 8$ de salário mínimo por mês (Barreto, Manso \& Santos, 2008).

Tais dados representam, em termos estatísticos, o agravamento de questões relativas à crescente dificuldade dos indivíduos inseridos nesses contextos de terem suas necessidades básicas de acesso à alimentação, moradia e educação atendidas. Aliado a essas restrições, aponta-se, também, a qualidade e pertinência dos serviços públicos oferecidos a essa parcela da população e a privação de suas liberdades pessoais.

A pobreza, então, se imprime no dia a dia dos povos latino-americanos e a eles impõe a convivência com situações de desigualdade social relacionada às disparidades de renda, existindo uma minoria de ricos e uma maioria de pobres (Góis, 2008; Martín-Baró, 1998). Esse tipo de desigualdade, dentro do contexto neoliberal, é produto de uma ideologia que dá continuidade e legitima o capitalismo, intensificando-se como condição necessária ao desenvolvimento econômico.

Em benefício da acumulação de riquezas, o eixo estruturador da sociedade capitalista passa a se ancorar, dentre outros elementos, na perspectiva de exploração dos seres humanos, propagando promessas de riquezas para aqueles que consigam se manter nessa dinâmica. Em contrapartida, aquele que não se adaptar a essas condições será

2 O salário mínimo base é referente ao ano de 2007 que custava em torno de R\$ 380,00 reais segundo o Guia Trabalhista (2009), ou US\$190,95 dólares em relação à cotação do dólar no respectivo ano. 
responsabilizado por seu insucesso, mascarando, assim, a dialética dominação-opressão (Santiago, 2007) presente nas relações de mercado.

Dessa forma, a visão constantemente difundida pela sociedade sobre os pobres estão associadas:

a) a uma culpabilização pelos seus fracassos;

b) ao desenvolvimento de discursos sobre sua (in)competência em obter um determinado padrão de vida;

c) e sua associação à violência (Euzébio Filho \& Guzzo, 2009).

Difundem-se, então, concepções negativistas quantos aos pobres, sem que análises abrangentes e históricas sejam empreendidas a partir do ponto de vista desse sujeito. À medida que a lógica de mercado e a acumulação de bens são colocadas em primeiro plano, as peculiaridades dos modos de vida são ignoradas e a desigualdade social toma proporções maiores, causando sofrimento e alienação na grande maioria da população. Como afirma Guzzo e Lacerda Jr. (2007, p. 232), o que é pior é que esse fenômeno adquire ares de trivialidade, passando a não mais incomodar; ao contrário, "as pessoas vão se acostumando e tudo começa a fazer parte do cotidiano, mascarando sentimentos e disposição para a vida".

A distribuição desigual dos recursos de uma nação passa a permear as relações sociais por atos de submissão (Martín-Baró, 1998). Dessa forma, o fator econômico e a configuração social da realidade influenciam na forma como as pessoas relacionam-se umas com as outras. Há imposição da vontade de uns perante os outros, posicionando seres humanos como indivíduos-objetos, dependentes, submissos, conformados e culpados pela sua condição social (Góis, 2008).

A opressão, nesse contexto, significa a negação da identidade do povo latino-americano pelo opressor, tornando sua existência comprimida e contida (Góis, 2008). Além disso, as relações de dominação e de opressão são mais complexas do que a explicação das lutas de classes entre pobres e ricos. O próprio povo que vive situações de opressão pode tornar-se opressor dos próprios pares.

Constrói-se, assim, uma teia complexa em que as relações de poder e de opressão são inseridas no psiquismo humano. Isso acontece porque, segundo Vygotsky (2004) e Bruner (1997), qualquer atitude tem uma gênese social, consequentemente está baseada na forma como se deram as interações sociais e a configuração da sociedade para o indivíduo e como essa pessoa posicionou-se nessas situações.

Nesse sentido, diante desse panorama de pobreza que pode "[...] ser facilmente verificada em cada favela das cidades latino-americanas, em cada sinal de trânsito, em cada rua" (Porto, 2010, p. 4) e em cada ser humano, ratifica-se a necessidade de que a psicologia se manifeste, de modo a anunciar em que sentido suas construções podem colaborar com a transformação dessa realidade.

\section{Psicologia e Pobreza: Diálogos possíveis (e necessários)}

Martín-Baró ([1990] 2009) aponta que, inicialmente, a Psicologia contemporânea foi convidada a refletir sobre questões relativas à necessidade das sociedades ocidentais em adquirir níveis cada vez maiores de aprimoramento e satisfação pessoal. Esse anseio, contudo, revelava-se em grupos nos quais as necessidades inerentes à sobrevivência já haviam sido satisfeitas. Colocavam-se, então, à margem do olhar psicológico, aqueles sujeitos cujos anseios poderiam ser facilmente materializados; ao passo que, no centro das reflexões, impunham-se os indivíduos com problemas decorrentes de sua fartura e que, numericamente, representam uma minoria da população.

À psicologia de meados do século XIX e início do século XX foi dada o lugar de prática dotada de características de neutralidade, objetividade, experimentação e tecnicismo. Havia uma clara reprodução de conceitos e procedimentos diagnósticos tendo em vista facilitar o campo de intervenção, prevenir e/ou eliminar comportamentos considerados desviantes e conflitantes (Nascimento, Manzini \& Bocco, 2006). Conforme afirma Sloan (2009, p. 227), "[...] a Psicologia, sistematicamente, tornou a si mesma irrelevante para os debates na economia e na política, porque falhou em incluir perspectivas interdisciplinares mais amplas sobre a sociedade na formação dos psicólogos".

Atualmente, entretanto, a proposta de Martín-Baró (2009) de que devemos redefinir o papel social da Psicologia na América Latina ganha maior importância, repercutindo em uma forma de fazer Psicologia que, segundo Ximenes e Barros (2009), está voltada para um compromisso ético e político em relação à maioria da população oprimida latino-americana. 
Uma atuação em Psicologia que se volte para a maioria marginalizada da população da América Latina, deveria, dentre outras coisas, fomentar a criticidade dos povos, fortalecer os movimentos populares, a luta reivindicatória, o diálogo e a transformação positiva da realidade (Vieira \& Ximenes, 2008).

Nesse sentido, concebendo a legítima relevância que os trabalhos em psicologia possuem para a maioria dos povos marginalizados submetidos à submissão e alienação por condições de vida marcadas pela pobreza, impõem-se questões de ordem epistemológica, conceitual e práxica que devem ser respondidas (Martín-Baró, 2009).

Epistemologicamente deve-se pensar quais os critérios de verdade comumente utilizados para legitimar o conhecimento em psicologia e a serviço de quem (ou de quê) são estruturados. A partir do momento que se pretende uma psicologia para a América Latina, deve-se partir dessa realidade para formular conhecimentos coerentes com seus anseios.

A dimensão conceitual está intimamente relacionada à questão epistemológica ao enfatizar a importância da análise crítica daquilo que as teorias não apreendem ou atribuem concepções valorativas comumente negativas. Por sua vez, a questão práxica discorre sobre o que hacer ${ }^{3}$ do psicólogo, afinal, "qual tem sido e qual é a contribuição da psicologia ao desenvolvimento integral dos povos latino-americanos?" (Martín-Baró, [1990] 2009, p. 203).

Montero (2006), Góis (2005) e Ximenes \& Barros (2009) afirmam que a Psicologia deve posicionar-se ativamente na construção de novas mudanças sociais, de novas compreensões de mundo e de novas interações sociais. Isso, a partir de atuações em cooperação com os povos marginalizados, transformando concretamente e simbolicamente a realidade social.

Assim, em uma sociedade na qual impera a pobreza, entende-se que há formas singulares de estruturação do psiquismo que contribuem para emergência de categorias psicológicas específicas, as quais serão apresentadas mais claramente no tópico a seguir.

\section{As categorias psicológicas emergentes em condições de pobreza}

A população pobre encontra suas raízes de submissão e conformismo na própria sociedade, visto que esta se estrutura de modo a reproduzir ideologias, relacionamentos, instituições e atitudes que estão a serviço da permanência de uma realidade de opressão. Percebe-se que a perpetuação da ideologia, compreendida neste trabalho como sistema de práticas e representações que mantêm e reproduzem relações de injustiça social (Moreira \& Sloan, 2002), funcionaria como instrumento de manutenção do binômio dominação-opressão.

De acordo com Góis (2008), a essa dimensão ideológica corresponde a Ideologia de Submissão e Resignação que é:

uma lógica de dominação ou sistema de ideias, valores, crenças, conhecimentos, atitudes, normas, leis, práticas sociais e institucionais que defina as condições e o modo coletivo de viver da classe oprimida [...] Nessa ideologia, a população pobre é vista como subalterna, serviçal, periférica, problemática, mão de obra barata e incapaz de protagonizar sua vida (Góis, 2008, p. 53).

Ela se manifesta nos diversos âmbitos de convivência do indivíduo e, progressivamente, altera a crença que possui sobre ser capaz de realizar algo pessoal e socialmente e assim agir com consciência e autonomia (Góis, 2003). 0 indivíduo "é empurrado para o enrijecimento, alienação e anomia, tendendo a se tornar um jovem ou um adulto hostil e/ou servil, portanto, ajustado à ideologia dominante" (Góis, 2008, p. 53).

A dominação impera por meio do estabelecimento de uma Cultura do Silêncio (Freire, 1980), na qual os sujeitos se configuram como perpetuadores silenciosos das práticas de dominação imbricadas em seu cotidiano. Não há indagação quanto aos fatos, pois estes se configuram como a única realidade possível e já anunciada para o povo.

A partir dessa realidade, observa-se, assim, a criação de uma das faces da identidade do indivíduo pobre: a Identidade de Oprimido e de Explorado.

\footnotetext{
3 Expressão utilizada nos textos originais de Ignácio Martín-Baró e que, a fim de manter seu significado original, optou-se por não traduzi-lo nesse artigo
} 
Segundo Góis (2008), ela pode gerar diversos posicionamentos pessoais de servilismo, de fatalismo e de violência, construindo um modo ou estilo de viver petrificado que tem como objetivo proteger os sujeitos das condições sociopsicológicas adversas às quais estão submetidos.

0 indivíduo não consegue se desvencilhar facilmente dessa Ideologia de Submissão e de Resignação (Góis, 2008) e dessa Identidade de Oprimido e de Explorado (Góis, 2008). Isso porque, a partir de sua inserção em uma realidade de opressão, ele tem seu psiquismo constituído com os significados manejados em uma cultura que o fornece, geralmente, formas de subjetivação que estão voltadas para o conformismo, para a apatia e para a violência.

0 fatalismo, nesse sentido, representa um fenômeno psicossocial intimamente relacionado com o modo como os indivíduos experienciam essas condições de vida. Ele é marcado pelo conformismo dos grupos e indivíduos com condições deploráveis de existência e um regime de vida opressor (MartínBaró, 1998). Expõe, ainda, sobre a visão que o indivíduo tem sobre o mundo, seu entorno e as relações que estabelece. Refere-se a uma postura adotada pelos sujeitos sobre si e sua vida e

constituye una relación de sentido entre lãs personas e un mundo al que encuentran cerrado e incontrolable; es decir, se trata de uma actitud continuamente causada y reforzada por el funcionamiento opresivo de las estructuras macrosociales. El niño de lãs favelas [...] marginales introjecta el fatalismo no tanto como uma herancia paterna, cuanto como eu fruto de su própria experiência frente a la sociedad (MartínBaró, 1998, p. 89-90). ${ }^{4}$

Inserido em uma circunstância de pobreza, a grande amarra do indivíduo seriam os elementos culturais estabelecidos frente a esta situação, pois o fatalismo serviria como uma profecia realizadora daquilo que ela já havia sido anunciado, definindo, com isso, um presente e um futuro predeterminados e que vão, silenciosamente, sendo aceitos passivamente, sem que grandes questionamentos sejam empreendidos. Assim, estabelece-se um círculo de manutenção da cultura da pobreza, pois, ao não fazer esforços para sair dessa situação, instaura-se o que Ardila (1979 citado por Martín-Baró, 1998) designa como impotência ou desesperança aprendida que, mesmo mudando e evoluindo as condições sociais, manteria a indolência fatalista.

Em outras palavras, afirma Martín-Baró (1998, p. 89):

[...] una vez establecida la cultura de la pobreza, em ella radicará la causa del fatalismo de la población, independientemente de que las condiciones sociales cambien o no. El fatalismo echaría sus raíces en el psiquismo de las personas más que en el funcionamiento de las estructuras econômicas, políticas e sociales. ${ }^{5}$

O fatalismo no latino-americano poderia ser examinado em uma tripla vertente afetiva, comportamental e ideacional (Martín-Baró, 1998). Na dimensão dos sentimentos, há a resignação frente ao próprio destino, o distanciamento emocional e a aceitação do sofrimento; nas ações, há a submissão, o conformismo, a passividade e a falta de memória e perspectivas; já as ideias se caracterizam pela pré-definição da vida e pela religião.

Observando-se os modos de expressão do fatalismo, poderíamos afirmar, em convergência com o apontado por Guzzo e Lacerda Jr. (2007), que fatalismo e impotência seriam fenômenos psicossociais que existiriam reciprocamente. Assim,

diante da impossibilidade de se fazer qualquer coisa pelo poder determinante que fatores têm sobre nossas vidas, o homem perde seu sentido de luta pela concretização de seus sonhos, sente-se predestinado ao seu destino e incapaz de agir sobre ele (Guzzo \& Lacerda Jr., 2007, p. 233).

4 Tradução nossa: “Constitui uma relação de sentido entre as pessoas e um mundo que se encontra fechado e incontrolável, quer dizer, se trata de uma atitude continuamente causada e reforçada nas estruturas macrossociais. A criança das favelas marginais [...] introjeta o fatalismo não tanto como uma herança paterna, mas como fruto de sua própria experiência frente a sociedade".

5 Tradução nossa: "Mitificação das forças históricas como natural ou como Deus”. 
Há, com isso, o que Martín-Baró (1998, p. 97) chama de "mitificación de las fuerzas históricas como naturaleza de Dios", 6 o que motiva o indivíduo a explicar os fatos cotidianos que lhe são dolorosos por meio dos fenômenos da natureza ou da vontade de uma entidade superior, ambos impossíveis de serem controlados. Estabelecendo-se essas equivocadas justificativas, o sofrimento se cristalizaria na forma daquilo que Sawaia (2009, p. 370) chama de potência de padecimento, ou seja, "de reação e não de ação, na medida em que as condições sociais se mantêm, transformando-se em um estado permanente da existência".

Apesar da amarra silenciosa representada pelo esquema fatalista, ${ }^{7}$ a dominação psicológica do colonizado, de acordo com Fanon (1972 apud MartínBaró, 1998), nunca é completa. Ele está dominado, mas não domesticado; está inferiorizado, mas não convencido de sua inferioridade. Ao contrário, há indícios de que o próprio fatalismo seria uma alternativa para lidar com esta situação de dominação, afinal, "em última instância, a raiz do fatalismo não está na rigidez mental das pessoas, mas na imutabilidade das condições sociais frente ao que as pessoas e grupos existem e se formam" (Martín-Baró, 1998, p. 98).

Evidencia-se, dessa maneira, que as características psicológicas do povo pobre latino-americano têm como objetivo a formação de uma constituição psíquica que suporte as condições adversas, opressoras e marginalizantes presentes na América Latina, funcionando como estratégias de sobrevivência do ser humano imerso e constituído em condições adversas e opressoras. Observa-se que a anulação do sofrimento, da angústia e do desespero do povo pobre em compreender sua realidade como opressora e marginalizante é fundada em uma reação adaptativa a essa realidade latino americana.

Assim, caso não houvesse essas estratégias psíquicas de sobrevivência alicerçadas pelo fatalismo e pela identidade de oprimido e de explorado, a vida do povo latino americano estaria anulada. Além disso, percebe-se que por mais opressora e por mais arraigada essas estratégias de sobrevivência estejam na constituição psíquica do povo latino americano, compreende-se, segundo Góis (2003, 2005, 2009), Vieira e Ximenes (2008) e Martín Baró (1998) o ser humano como primordialmente potencial. Apesar das práticas, das interações e das ideologias presentes na América Latina estarem permadas por opressão, percebe-se que não se extermina a capacidade do ser humano de desenvolver-se e de expandir-se em suas potencialidades.

Contudo, embora o fatalismo e a identidade de oprimido e de explorado não determine uma completa rigidez mental, podem influenciar profundamente os modos de estruturação do psiquismo dos indivíduos ao interferirem na maneira como os sujeitos compreendem os fenômenos e encontram alternativas para superarem os problemas advindos de situações complexas. Há, em certos momentos, a dificuldade de construção de uma cadeia lógica de compreensão dos fatos à medida que o processo histórico que o ocasionou é ignorado ou distorcido pelos sujeitos. Esse fenômeno se deve, em parte, ao processo de marginalização oriundo da pobreza e que "produz experiências, identidades, representações e tipos de comportamentos que caracterizam uma forma de vida" (Tripodi, 2005, p. 16).

Assim, observa-se que a forma como a realidade está estruturada, a maneira como se apresentam as interações sociais e os moldes como se estabelecem os significados negociados nessa realidade são constituintes do psiquismo humano (Fittipaldi, 2006; Vygotsky, 2004).

Para tanto, escolhe-se a Teoria Histórico Cultural da Mente, a partir das contribuições de Lev Vygotsky (1896-1934), para entender a repercussão dessa realidade de pobreza no psiquismo humano. Para o autor, o psiquismo humano tem uma gênese social. Suas concepções estão, ainda, amparadas no materialismo histórico dialético, ou seja, o ser humano está em constante transformação a partir da interação social com outros pares, imerso em uma realidade social que está o constituindo (Barros et al., 2009; Góis, 2005; Vygotsky \& Luria, 1996; Vygotsky, 2004; Ximenes \& Barros, 2009).

\footnotetext{
6 Tradução nossa: “Uma vez estabelecida a cultura da pobreza, nela estará a causa do fatalismo na população, independentemente se as condições sociais mudem ou não. 0 fatalismo deixará suas raízes no psiquismo das pessoas mais que no funcionamento das estruturas econômicas, políticas e sociais".

7 Martín-Baró em seu livro 'Psicología de la liberación' (1998) utiliza os termos síndrome fatalista latino-americana, esquema fatalista e caráter fatalista para se referir a essa visão peculiar do indivíduo sobre sua vida.
} 
Nesse sentido, a produção de formas de existência latino-americanas singulares a partir da realidade da pobreza acontece em virtude do duplo desenvolvimento humano que Vygotsky (2004) intitulou de funções psicológicas superiores. ${ }^{8}$ Primeiramente, para esse autor, elas se situam em um nível interpsicológico para, em seguida, desenvolverem-se em um nível intrapsicológico. A constituição do âmbito intrapsíquico é reflexo da realidade social em que pessoa entrou em contato, sendo a linguagem a via de reprodução dessa realidade para o âmbito psíquico.

Explica-se, dessa maneira, que a experiência social, para Vygotsky (2004), produz o psiquismo por meio do contato dos seres humanos com outros pares de uma mesma cultura mediados pela linguagem. Esta é constituída de signos - palavras, sinais matemáticos, mapas, desenhos, dentre outros - que o ser humano aprende a manejá-los e usá-los para comunicação externa e, depois, consigo mesmo. 0 signo, então, passa a ser um instrumento psicológico de criação de novas conexões entre as funções psíquicas quando interiorizado.

Esse processo somente acontece, para Vygotsky (2004), porque existem significados que são conceitos estáveis da palavra, dos signos, que criam um solo comum para a comunicação e para generalização, permitindo aos indivíduos estabelecerem uma via de compreensão de si e dos outros por meio do erguimento de uma lei que estrutura essas conexões regulares da generalização. Esses significados estão situados, primeiramente, entre os seres humanos em uma cultura para, em seguida, fazerem parte do âmbito psíquico, modificando-o e sendo modificados por ele, fundamentando, assim, a mediação semiótica do psiquismo.

Observa-se que esses significados têm em sua base uma valoração social representando as ideologias vigentes em uma cultura que ditam a criação de novas conexões. Assim,

é preciso assinalar, por um lado, a conexão que alguns sistemas novos mantêm não só com signos sociais, mas também com a ideologia, e o significado que tal ou qual função psicológica adquire na consciência das pessoas, ao passo que, por outro lado, o processo de aparecimento de novas formas de comportamento a partir de um novo conteúdo é extraído pelo homem da ideologia do meio que o rodeia (Vygotsky, 2004, p. 117).

Vygotsky (2004) traz que existem diferenças entre as classes sociais e as características psicológicas. "Os traços sociais e de classe formam-se no homem a partir de sistemas interiorizados, que nada mais são do que os sistemas e relações sociais trasladados para a personalidade" (Vygotsky, 2004, p. 133). Significa dizer que as interações sociais, o contexto cultural de desenvolvimento da pessoa, as ideologias presentes e os significados que esse indivíduo aprendeu a manejar podem criar formas singulares de constituição humana.

Dessa forma, a diferenciação dos sujeitos em classes sociais reflete em um determinado padrão de relacionamento social que estrutura seu cotidiano, influenciando seu processo de desenvolvimento humano (Waiselfisz, 2004) e psicológico (MartínBaró, 2000 apud Euzébios filho \& Guzzo, 2006), Este processo deve ser compreendido tomando como base os elementos que contribuem para essa distinção em níveis socioeconômicos, culturais, ideológicos e políticos.

Colocado em evidência que os significados estão constituídos como instâncias ideológicas que fornecem a base para o desenvolvimento do psiquismo, nota-se que há o reflexo psíquico dessa realidade de opressão e de submissão na vida dos mais pobres da América Latina. Eles assimilam posições servis, subalternas e fatalistas a partir da forma como são posicionados na sociedade a partir das ideologias dominantes.

No contexto latino-americano, esses significados estão construídos de tal maneira que a população pobre se sente impotente frente à estruturação da realidade. Tendo "aprendido" desde cedo que é incapaz de transformar sua vida, a Ideologia de Submissão e de Resignação (Góis, 2008) contribui para a manutenção desse complexo ideológico, das relações de poder e da estrutura hierárquica da sociedade, assim como a síndrome fatalista.

Nesse sentido, a rede de significados construídos nesse contexto está voltada para a reprodução

8 Vygotsky (1998) enfatiza que o desenvolvimento do psiquismo e o comportamento humano devem ser explicados a partir das funções psicológicas superiores (pensamento, linguagem e consciência), funções estas oriundas da convivência social a qual todos os indivíduos são submetidos ao longo se sua existência. 
da ordem social vigente ao contribuir para a perpetuação do sistema de crenças e de valores de que a realidade é imutável. A responsabilidade pela estruturação da sociedade é atribuída a acepções divinas que culpabilizam a população pobre pelas suas condições de vida, reforçam ideias individualistas e minam movimentos reivindicatórios e políticos em prol de melhorias para coletividade.

Dessa maneira, os significados, que criam o solo comum para compreensão da realidade e para construção dos sentidos, podem fornecer um panorama de criação de sentidos que é reduzido. Os sentidos são construídos a partir das vivências afetivas, as experiências de vida e os contextos de uso dos significados em uma realidade opressora. Assim, os sentidos podem ser reduzidos às significações vigentes. Portanto, os significados que possuem uma base opressora podem tornar-se muito próximos dos sentidos que passam a ter também essa valoração.

Isso acontece porque o ser humano possui conexões pessoais - os sentidos - que extrapolam as formações estáveis presentes no significado. Essas concepções se referem aos sentidos que estão balizados pelas motivações, pelas vivências afetivas vividas e pelo seu contexto de uso. Os sentidos são mais instáveis e se referem à soma de todos os fatos psicológicos que uma palavra desperta na consciência, possuindo, então, um caráter múltiplo e indeterminado. Dessa maneira, o sentido tem uma abrangência mais ampla, extrapolando as bases dos significados (Vygotsky, 2004).

Observa-se, então, que, apesar da rede de significados culturais vinculados a uma Ideologia de Submissão e de Resignação, uma Cultura do Silêncio e uma Síndrome Fatalista, o ser humano tem a possibilidade de desenvolver seu psiquismo em bases mais abrangentes do que as práticas e crenças vigentes.

Como coloca Sawaia (2009) e Góis $(2003,2008)$, o ser humano deve ser encarado como repleto de potencialidades, pois, embora existam estruturas cerceadoras de liberdade, há, em contrapartida, possibilidades de mudança e de transformação. 0 indivíduo pode encontrar as mais variadas alternativas para sobreviver em condições de existência desumana, demonstrando, com isso, seu potencial de (re)agir frente às condições adversas, pois, como coloca Vygostky (1993 apud Sawaia 2009), a base de seu psiquismo é a imaginação, a criatividade e a expansão.
Demonstra-se, assim, a significativa repercussão da realidade da pobreza na constituição psíquica do ser humano. Percebe-se que as bases sociais e ideológicas de manutenção da pobreza são também constituintes do âmbito psíquico apesar da existência de potencialidades inerentes ao ser humano.

\section{Considerações finais}

Conclui-se que compreender a pobreza como multidimensional expande a abrangência de suas influências na constituição humana. Assim, visualiza-se a pobreza não somente restrita no parâmetro da economia, mas voltada também para o âmbito da liberdade, da interação social e da ideologia.

Percebe-se, então, a América Latina e o Brasil como territórios onde se concentram diversas e significativas formas de pobreza. 0 povo latino-americano está inserido em uma realidade de opressão e de marginalização que o posiciona em um lugar de culpado pela sua situação, de conformado com sua realidade e de incapaz de promover alguma mudança na sua vida. Essas premissas estão alinhadas às correntes ideológicas que objetivam a manutenção do status quo, que tem uma grande influência na constituição do psiquismo.

Por isso, demonstra-se a relevância de voltar o olhar psicológico para os seres humanos imersos na realidade de pobreza da América Latina. Enfatiza-se como essencial o debruçar-se da Psicologia para a maioria da população latino-americana que vive em condições de pobreza, mas que estão distantes das considerações da Psicologia vigente, que, geralmente, está disposta a inclinar-se sobre as questões de uma minoria populacional distante da uma realidade de pobreza.

Nota-se, dessa forma, a necessidade de estranhamento e de questionamento da construção de um conhecimento psicológico voltado para uma população imersa em condições satisfatórias de sobrevivência distante das condições adversas e opressoras de vivência. Martín-Baró (1998) atenta para os objetivos e para as premissas arraigadas em formas de fazer Ciência vigente voltadas para posturas acríticas e descompromissadas com a realidade social, geralmente, tendo como princípio a manutenção do status quo.

Dessa maneira, evidencia-se como imprescindível a imersão da Psicologia nessa realidade 
latino-americana, pois se entende a realidade de pobreza como cenário de constituição do psiquismo humano. Observa-se que a Ideologia de Submissão e de Resignação (Góis, 2008), a Cultura da Pobreza (Martín-Baró, 1998), a Cultura do Silêncio (Freire, 1980) e a Síndrome Fatalista (Martín-Baró, 1998) estão dispostas nos significados presentes na realidade latino-americana. Elas carregam valores de anulação da capacidade de transformação da realidade pelo indivíduo, de imutabilidade das estruturas sociais marginalizantes e de crença em uma entidade divina ou em forças da natureza para mudanças sociais.

Esses valores também fazem parte da constituição psíquica da população que está inserida na realidade da pobreza. Percebe-se, então, que os sentidos são regidos por esses significados, construindo um campo de compreensão da realidade que estão balizados por esses valores sociais opressores. No entanto, conclui-se que, apesar da prevalência de crenças e práticas opressoras, encara-se o ser humano como potencial baseado em sua capacidade de expandir e de superar as significações vigentes a partir dos sentidos que são múltimos, instáveis e criativos.

\section{Agradecimentos}

Agradecemosà Coordenação de Aperfeiçoamento de Pessoal de Nível Superior (CAPES) pelo financiamento das bolsas de mestrado para a realização desta pesquisa.

\section{Referências}

Avis. (2010). Lojas Avis na América Latina. Recuperado em 10 ago. 2001, em http://portugues.avis-int.com/ directorio/latam/directoriolatam_mapa.html

Barreto, F. A., Manso, C. A., \& Santos, J. A. S. (2009). 0 mapa da extrema indigência no Estado do Ceará e o custo financeiro de sua extinção. Recuperado em 10 jun. 2009, em www.caen.ufc.br/ lep/notastecnicas/nota4.pdf

Barros, J. P. P., Paula, L. R. C. de, Pascual, J. G., Colaço, V. de F. R., \& Ximenes, V. M. (2009). O conceito de "sentido" em Vygotsky: Contribuições epistemológicas e suas implicações para a investigação psicológica. Psicologia \& Sociedade, 21(2), 174-181.
Bruner, J. (1997). Atos de significação. Porto Alegre: Artes Médicas.

Castro, J. (2004). Geografia da fome: 0 dilema brasileiro pão ou aço. Rio de Janeiro: Civilização Brasileira. (Publicação original em 1943).

Comisión Econômica para América Latina y Caribe CEPAL. (2009). Anuário estadístico para América Latina y Caribe. Recuperado em 15 ago. 2010, em http://websie.eclac.cl/anuario_estadistico/anuario_2009/esp/default.asp

Diniz, M. B., \& Arraes, R. A. (2007). Novas evidências para as taxas de pobreza no Brasil. Recuperado em 10 jun. 2009, em http://www.caen.ufc.br/ lep/ Ensaios/Ensaios\%20sobre\%20Pobreza\%2010.pdf

Euzébios F, A., \& Guzzo, R. S. L. (2006). Fatores de risco e de proteção: Percepção de crianças e adolescentes. Temas em Psicologia, 14(2), 125-141.

Fittipaldi, C. B. (2006). As influências que as ideias marxistas exerceram sobre Vygotsky. Revista da Educação, 1(1), 74-78.

Freire, P. (1980). Conscientização: Teoria e prática de libertação. São Paulo: Moraes.

Góis, C. W. L. (2003). Psicologia comunitária no Ceará: Uma caminhada. Fortaleza: Instituto Paulo Freire de Estudos Psicossociais.

Góis, C. W. L. (2005). Psicologia comunitária: Atividade e consciência. Fortaleza: Instituto Paulo Freire de Estudos Psicossociais.

Góis, C. W. L. (2008). Saúde comunitária: Pensar e fazer. São Paulo: Hucitec.

Guzzo, R. S. L., \& Lacerda Jr., F. (2007). Fortalecimento em tempo de sofrimento: Reflexões sobre o trabalho do psicólogo e a realidade brasileira. Revista Interamericana de Psicologia, 41(2), 231-240.

Instituto Brasileiro de Geografia e Estatística - IBGE. (2007). Contagem da população 2007. Recuperado em 10 jul. 2010, em http://www.ibge.gov.br/home/ estatistica/populacao/contagem2007/default.shtm

Lacerda, F. C. C. (2009). A pobreza na Bahia sobre o prisma multidimensional: Uma análise baseada na abordagem das necessidades básicas e na abordagem das capacitações. Dissertação Mestrado do Programa de Pós-Graduação em Economia do Instituto de Economia, Universidade Federal de Uberlândia, Uberlândia. 
Laderchi, C., Saith, R., \& Stewart, F. (2003). Does it matter that we don't agree on the definition of poverty? A comparison of four approaches. Recuperado em 11 fev. 2009, em http://ideas.repec.org/q/qeh/ qehwps/qehwps107.html

Martín-Baró, I. (1998). Psicología de la liberación. Madrid: Trotta.

Martín-Baró, I. (2009). Desafios e perspectivas da psicologia Latino-Americana. In R. S. L Guzzo, \& F. Lacerda Jr. (Org.). Psicologia Social para a América Latina: 0 resgate da Psicologia da Libertação (pp. 199220). São Paulo: Alínea.

Mendonça, G. C. (2006). Os sentidos subjetivos moradores de rua frente ao futuro. Dissertação de Mestrado do Programa de Pós-Graduação em Psicologia, Pontifícia Universidade Católica de Campinas, Campinas.

Montero, M. (2006). Hacer para transformar: El método en la psicología comunitaria. Buenos Aires: Paidós.

Moreira, V., \& Sloan, T. (2002). Personalidade, ideologia e psicopatologia crítica. São Paulo: Escuta.

Nascimento, M. L., Manzini, J. M., \& Bocco, F. (2006). Reinventando as práticas Psi. Psicologia \& Sociedade, 18(1), 15-20.

Néri, M. C. (2007). Miséria, desigualdade e políticas de transferência de renda: 0 real do Lula. Rio de Janeiro: FGV/IBRE, CPS. Recuperado em 15 ago. 2010, em http://www.fgv.br/cps/pesquisas/site_ ret_port/RET_Texto.pdf

Osório, J. M. F. (2009). Ética e construção social da libertação Latino-americana. In R. S. L. Guzzo, \& F. Lacerda Jr. (Org.). Psicologia social para a América Latina: 0 resgate da psicologia da libertação (pp. 65-84). São Paulo: Alínea.

Porto, M. S. (2009). Exclusão socioeconômica nos espaços urbanos da América Latina: 0 novo mundo e a desigualdade. Recuperado em 14 ago. 2010, em http://egal2009.easyplanners.info/area05 /5339_Marilia_Serena_P_S_.pdf
Salama, P., \& Destremau, B. (2002). Medidas de pobreza desmedida: Economía política de la distribución del ingreso. Santiago: LOM Ediciones.

Santiago, G. L. (2007). Filosofia da libertação. Filosofia Ciência \& Vida, 14(1), 38-49.

Sawaia, B. B. (2009). Psicologia e desigualdade social: Uma reflexão sobre liberdade e transformação social. Psicologia \& Sociedade, 21(3), 364-372.

Sen, A. (2000). Desenvolvimento como liberdade. São Paulo: Companhia das Letras.

Sprandel, M. A. (2004). A pobreza no paraíso tropical: Interpretações e discursos sobre o Brasil. Rio de Janeiro: Relume Dumará.

Sloan, T. (2009). Globalização, pobreza e justiça social: Papéis para os psicólogos. In R. S. L. Guzzo, \& F. Lacerda Jr. (Org.). Psicologia social para a América Latina: 0 resgate da psicologia da libertação (pp. 223-244). São Paulo: Alínea.

Tripodi, M. A. L. (2005). Da maré para o seco: Família, moradia e pobreza. Dissertação de Mestrado do Programa de Pós-Graduação. Mestrado em Ciências da Família na Sociedade Contemporânea, UCS, Salvador.

Vieira, E. M., \& Ximenes, V. M. (2008). Conscientização: Em que interessa este conceito à psicologia. Psicologia Argumento, 26(52), 23-33.

Vygotsky, L. S. (1998). A formação social da mente. São Paulo: M. Fontes.

Vygotsky, L. S. (2004). Teoria e método em psicologia. São Paulo: M. Fontes.

Vygostky, L. S., \& Luria, A. (1996). Estudos sobre a história do comportamento: 0 macaco, o homem primitivo e a criança. Porto Alegre: Artes Médicas.

Ximenes, V. M., \& Barros, J. P. P. (2009). Perspectiva histórico cultural: Que contribuições teórico-metodológicas podem dar à práxis do psicólogo comunitário? Psicologia Argumento, 27(56), 65-76.

Waiselfisz, J. J. Relatório de desenvolvimento juvenil 2003. Recuperado em 15 ago. 2005, em http://unesdoc.unesco.org/images/0013/001339/133976por.pdf 